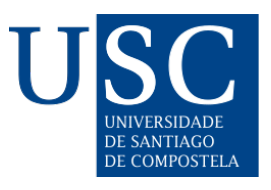

\title{
Democracia y seguridad. Respuestas para avanzar en el sistema público
}

\author{
Anxo Varela Hernández \\ Centro de Estudios de Seguridad (CESEG), Universidad de Santiago de Compostela, España
}

Las democracias, comprendidas como tales en tanto las nociones vigentes en pleno siglo XXI, encuentran uno de sus puntos débiles en la incerteza del mañana, en la volatilidad de los elementos que las componen, así como en la constante aparición de nuevas y antiguas amenazas que, en ocasiones, hacen quebrar alguno de sus pilares. Con esta premisa surge el libro Democracia y seguridad. Respuestas para avanzar en el sistema público, que se publica en el seno del proyecto que lleva por título Las respuestas en un Estado de Derecho a los retos de seguridad; fortalecimiento democrático, derechos fundamentales y deberes de la ciudadanía, concedido por el Ministerio de Economía, Industria y Competitividad de España; en estos instantes llamado Ministerio de Economía y Transformación Digital.

En la actualidad resulta más relevante que nunca analizar las cuestiones hiladas respecto del término seguridad desde la absoluta libertad académica y desde diferentes ópticas para, con ello, observar de un modo amplio las claras amenazas que se presentan frente, por ejemplo, a la seguridad nacional. Algunas de ellas nos acompañan desde hace años y, sin embargo, otras surgen de forma inopinada. En este último caso, el año 2020 ha sido clara muestra de ello, ya que se han puesto de relieve a nivel mundial multitud de nuevas circunstancias y problemáticas nacidas y desarrolladas en el seno de la pandemia provocada por la COVID-19. Estas últimas, tal y como relata el coordinador de este libro, José Julio Fernández Rodríguez (2020), no hacen más que poner de manifiesto "lo real de las amenazas sanitarias (como se constataba en documentos estratégicos anteriores, por ejemplo, en la Estrategia de Seguridad Nacional española de 2017...)” (p. 156). Asimismo, se pone de relieve no sólo en el ámbito estrictamente doctrinal sino también para los ciudadanos de a pie, la necesidad de la declaración de los estados excepcionales cuyo ámbito "en menor medida, es la seguridad ciudadana" en palabras de Ana Aba Catoira (2020, p. 234-235). Este debate no está exento de polémica debido a la, a veces, incorrecta ponderación de los términos libertad y seguridad; lo que en ocasiones conlleva una extensión del poder estatal en detrimento de las libertades ciudadanas que no solo se mantiene en las situaciones excepcionales que le pueden servir de sustento jurídico, sino que se extienden "sine die" con vocación de permanencia y de manera opaca. Temas, todos ellos, tratados en este libro de manera profusa, detallada y rigurosa, junto con otros de tremenda relevancia, entre los que se encuentran, por ejemplo, temas prácticos y llamativos para la ciudadanía en su conjunto como la videovigilancia, el terrorismo internacional o las personas víctimas de trata, y otros más teóricos y con un tremendo interés académico como las identidades de la democracia, los deberes de la ciudadanía o la evolución del Estado. 
Todo ello lo realiza un conjunto de autores de prestigio internacional que observan la realidad desde los diversos prismas que se pueden encontrar en el núcleo de las ciencias sociales y, desde los cuales, resulta imprescindible realizar un profuso análisis de esta materia: el Derecho internacional público, el Derecho constitucional, la Ciencia Política y el Derecho público comparado entre otros.

Buscando que el libro pueda ser, no sólo objeto del análisis de expertos en la materia sino de cualquier ciudadano con interés en este ámbito, Democracia y seguridad. Respuestas para avanzar en el sistema público se ha estructurado en dos partes. En primer lugar, una parte general que permita adquirir y/o profundizar en temáticas de corte más amplio o genérico (pero igualmente escrutadas de manera minuciosa), como la obra que da inicio al propio libro, elaborada por el catedrático de la Universidad de Bolonia Lucio Pegoraro. En segundo lugar, se encuentra una parte específica que incluye los trabajos que versan sobre temas más concretos; algunos de ellos con una formidable importancia en el momento actual, como el principio de proporcionalidad en los derechos fundamentales, analizado por Rubén Miranda Gonçalves.

Finalmente, la publicación de este libro se ha visto influenciada por la impronta que ha supuesto la COVID-19 en la vida de los ciudadanos de cualquier parte de un mundo ya marcado por la inestabilidad. Circunstancia, desde hace años analizada en el Centro mixto formado por la Universidad de Santiago de Compostela y el Centro Superior de Estudios de la Defensa Nacional: el CESEG. Su director cobija un colmado bagaje interdisciplinar; perspectiva acuciada por su experiencia en tanto Delegado de Protección de Datos de la USC y Ombudsman de la Comunidad Autónoma de Galicia.

Con todas estas premisas, se ha conformado un libro que aglutina un total de diecisiete artículos y que parte de la necesidad de analizar desde un punto de vista objetivo, dejando a un lado sentimentalismos, los posibles ataques al Estado de Derecho que, a veces, semejan ser inevitables en un mundo globalizado como el actual. Posible relación de causalidad que, de manera extremadamente sintética pero profunda, expone y discute en el libro Democracia y seguridad Federico Aznar Fernández-Montesinos. Siendo conscientes de los irremediables costes de oportunidad de vivir en un mundo en el que las distancias se han acortado (para lo bueno y lo malo), también se manifiesta la necesidad de articular mecanismos que protejan las democracias actuales de enemigos externos (como el terrorismo yihadista, estudiado por Juan Antón Mellón y Elisenda Antón Carbonell) y otros que surgen el seno de las democracias y como consecuencia de las libertades y el libre ejercicio de derechos que las caracterizan (como los nacionalismos y las nuevas identidades colectivas, consideradas en el fragmento autoría de Luis Velasco Martínez; o el populismo, elemento abordado por Arianna Vedaschi).

Asimismo, la internacionalización crea problemáticas que, en ocasiones, semejan no existir para occidente hasta que implican consecuencias prácticas para el día a día de sus ciudadanos, como la trata de personas; que rara vez forma parte de los debates mantenidos por la opinión publicada (y, en consecuencia, en los debates que surgen en la opinión pública). Sin embargo, temáticas como esta comienzan a resonar en el ideario de partidos radicales que también suponen un futurible, o incluso presente, problema a la estabilidad de las democracias, por aprovecharse estos de los mecanismos plurales y abiertos de las mismas con el fin de introducir debates inocuos desde el punto de vista del contenido, pero que sí que se transforman en verdaderas amenazas al ser expuestos a la ciudadanía de un modo nada bonancible y mucho menos diáfano. Además, resulta de todo orden procedente que el Estado luche contra lacras como la trata que, tal y como indica la autora Ana Marrades Puig, no solo atenta contra la seguridad de las personas que la padecen, sino también contra la seguridad nacional de los países en los que se produce. Por ello, 
resulta imprescindible a ojos de la autora, con fundamentación en la Estrategia Nacional contra el Crimen Organizado y la Delincuencia Grave 2019-2023, impulsar la cooperación internacional por el mercado transnacional de esta tipología criminal o reforzar la colaboración de todos los actores nacionales implicados. Necesidades también contempladas en este libro por María del Ángel Iglesias Vázquez. Ello, serviría no solo para minorar este nuevo modelo de esclavitud manifestado en el siglo XXI, sino también para soslayar los discursos de odio de los que beben ciertos extremos políticos. Sin embargo, realidades como las ahora citadas no deben atemorizarnos hasta el punto de la parálisis, ya que, como de manera rotunda sentencia el profesor Miguel Anxo Bastos Boubeta (2020), "los Estados son mucho más resistentes de lo que muchos teóricos piensan" (p. 300).

Del mismo modo, existen ciertas problemáticas que, aunque en el norte de la península ibérica (o del continente europeo) en ocasiones puedan semejar indiferentes o resultar inadvertidas, sí que florecen y permanecen en otros lugares del mundo o mismo del propio Reino de España. Se trata, pues, del mal llamado inframundo, surgido en torno a las drogas. La existencia de este supone una verdadera crisis en Latinoamérica por llevar aparejada la carencia de los estándares mínimos de seguridad que se deberían mantener y, consiguientemente, la constante vulneración de los derechos humanos que, en cierto modo, surge por la subordinación del control de drogas que se produjo tras la Segunda Guerra Mundial a otras temáticas como la economía. Ello pese a que surja la Comisión de Estupefacientes (CND), cuyas reuniones anuales siguen careciendo de la trascendencia pública que merece una problemática que engloba no solo violencia e inseguridad, sino también la ingobernabilidad en ciertos territorios cuyo motor son las políticas de prohibición; como desde un prisma cercano a estos problemas de dimensión internacional nos ofrece Mónica Serrano en buena parte de su observación.

En suma, el heterogéneo examen realizado por autores que han desarrollado sus estudios e incluso vidas en lugares diferentes y dispares del planeta, permite al lector profundizar en temas que a menudo surgen con forma de debate en las esferas públicas (ya sean políticas o mediáticas) pero que, en raras ocasiones, se contemplan de manera objetiva y se plantean con absoluta libertad de expresión. Por ello, estamos ante un libro incómodo para todo aquel que quiera seguir impasible frente a las problemáticas que inundan nuestros días, pero necesario para quien quiera conocer las amenazas, a veces escondidas a ojos del ciudadano, y, sobre todo, para comprender la necesidad de que los Estados, de manera conjunta, caminen en la erradicación de aquellas circunstancias amenazantes que nos acompañan desde el siglo pasado, y en el conocimiento y mitigación de las que, cada día, surgen como consecuencia primaria del mundo cambiante en el que desarrollamos nuestras vidas.

La pandemia provocada por la COVID-19 ha puesto de manifiesto la existencia de amenazas intangibles e inesperadas $\mathrm{y}$, por ende, la fragilidad del ser humano y la necesidad de analizar la posición de este frente al mundo. Dejando a un lado la perspectiva centrista que a veces mantiene la humanidad, debemos contemplar el universo que nos rodea de manera humilde y desconfiada, articulando mecanismos preventivos que permitan la protección del ciudadano en particular y de la democracia en general, pero sin vulnerar pilares básicos de todo Estado de democrático y de Derecho como la libertad o el principio de proporcionalidad en los derechos fundamentales. Finalmente, se suscita la necesidad del fortalecimiento democrático como garantía frente a los riesgos de la seguridad del siglo XXI, debido a la ineficacia de algunas otras respuestas y al protagonismo que en la actualidad cobra la ciudadanía a través de las redes y del activismo social del que también bebe el cuarto poder. 
Para rematar, no debemos olvidar que este libro crece, fundamentalmente, gracias al término seguridad, lo que implica que todo lo que en él se contiene goza de una perspectiva histórica pero también de una serie de matices volátiles o cambiantes; hecho acuciado por la rapidez en la que las últimas décadas avanzan en cuanto a descubrimientos, realidades y amenazas. Ello, unido al marcado carácter pedagógico que abraza la obra de estos autores, hace que Democracia y seguridad. Respuestas para avanzar en el sistema público no solo ofrezca soluciones sino también plantee preguntas que inviten a la reflexión y, cuyo debate, puede servir para que las democracias y los actores que en ellas se hallan se anticipen ante problemáticas cada vez más divergentes, fugaces e inesperadas.

\section{Información Adicional:}

Título: Democracia y seguridad. Respuestas para avanzar en el sistema público

Autor: José Julio Fernández Rodríguez (Coord.)

Editorial: Tirant lo Blanch

Año de edición: 2020

Páginas: 484

ISBN: 978-84-1355-851-6 